\title{
DEVELOPMENT OF ELECTRONIC TONGUE FOR SORGHUM QUALITY DETECTION
}

\author{
Suraj Kshirsagar ${ }^{1}$, R.P.Mudhalwadkar ${ }^{2}$ \\ ${ }^{I}$ Student, Department of Instrumentation and Control, College of Engineering Pune, Maharashtra, India \\ ${ }^{2}$ Associate Professor, Department of Instrumentation and Control, College of Engineering Pune, Maharashtra, India
}

\begin{abstract}
Due to insufficient and improper facility of storage available in India many grains affects by quality. Quality changes over time due to many things, one of them is moisture content of the cereals. This paper presents the design of a low-cost electronic tongue system with a personal computer based decision making system. Generally, this kind of concept for food quality determination has been used since many years for liquid food samples like coke, water, tea etc. Here the noble approach is applied for solid cereal food like sorghum, wheat etc. The designed system is able to implement Voltammetry measurement with standard three electrode configuration. Gold silver platinum and copper are used as electrode. Lab-View from National Instrumentation's is used to generate and gather the signals to and from electronic tongue setup. The data obtained from the electrochemical measurement of samples made from different variety of sorghum are applied to the artificial neural network analysis. First, the network is trained for different known samples which are categorized into 3 different classes on the basis of the varieties. The network is found to able discriminate them all accordingly.. The next experiment has shown that with the e-tongue graduation of the sample based on quality of the cereal sample can be done, where the quality is affected due to the moisture.
\end{abstract}

Keywords: Neural networks, Electronic tongue, Feature extraction, Cereals, Food quality etc. $* * *$

\section{INTRODUCTION}

The success of a food product in the food industry is determined by many physical characteristics like appearance, aroma and flavor. This makes the growing customer demand for food quality, more rigorous inspection and approval. In order to guarantee the quality of commercial drinks, like tea [1], coffee, juice [2] water [3][4], coke [5].

Different methods of chemical, physicochemical and sensory analysis are successfully utilized. But there is mere any research done for cereals, grains quality determination. The above said techniques include a series of well-known laboratory based methods like chromatographic and spectroscopic, which are able to categorize with great accuracy the chemical composition. The goal of the second ones, sensory method is to evaluate the sensations produced by food altogether. The sensorial analysis can be defined as the experimentation and analysis of the global characteristics of a product through the senses; those characteristics are known as organoleptic.

Taste and smell senses are known as chemical senses because they react to stimuli created by molecules starting a nerve reaction. Taste reacts to stimuli produced by food particles on the tongue's taste buds. This interaction creates the sensation of taste. The taste receptor cells are located above all on the taste buds. The mechanism by which different relishes detected and noticed is not yet ascertained, but it is known that taste cells respond with partial selectivity to a series of chemical compounds; in detecting a relish a series of electrical impulses are generated with different intensities and are transmitted to the brain, where they are compared to identify relishes. An inspiration has been generated so that from the taste and smell working principles, instruments may be developed so that to emulate its capacity to classify and differentiate many complex materials. These biologically inspired sensors are known as electronic tongues and noses. Thus, a particular analogy can be established between the human taste system and the electronic one in order to detect the complex materials. So that some approximations can be found in its structure and functioning principles.

Since the development of the first prototype in 1990 by K. Toko [9], electronic tongues are becoming some of the most promising tendencies to develop cheap, fast and promising method to evaluate food taste. A certain number of research groups have focused their work on the perfection and improvement of these systems by utilizing different strategies and measuring techniques. There are several techniques and different sensors have been employed in electronic tongues. Some of the combinations of sensor array used by different researches are given in the table 1.The most important ones are based on electrochemical techniques Voltammetry and potentiometry. Voltammetry is having advantage like veracity, simplicity and good sensitivity which lead to use this method over other electronic tongue methods [12].

People are getting more conscious about quality food which they consume. In most of the India there are many different varieties of cereals are produced and consumed. The market value of any agricultural product depends on its requirement 
and availability. On the basis of quality of sorghum, its taste and shelf life changes. Moisture Content changes the shelf life and quality of the cereals [12] [13]. In this paper quality of sorghum is tried to relate moisture content using the electronic tongue.

Table 1: Specifications of self-designed 3- electrode voltammetry electronic tongue used for different research work

\begin{tabular}{|l|l|l|l|l|l|}
\hline & $\begin{array}{l}\text { Water } \\
\text { authentication[4] }\end{array}$ & $\begin{array}{l}\text { Classification } \\
\text { of tea[6] }\end{array}$ & $\begin{array}{l}\text { Freshness of } \\
\text { milk [7] }\end{array}$ & $\begin{array}{l}\text { Classification of } \\
\text { Virgin Oin } \\
\text { Oils[8] }\end{array}$ & $\begin{array}{l}\text { Classification } \\
\text { Juices [9] }\end{array}$ \\
\hline $\begin{array}{l}\text { Reference } \\
\text { electrode }\end{array}$ & $\mathrm{Ag} / \mathrm{AgCl}$ & $\mathrm{Ag} / \mathrm{AgCl}$ & $\mathrm{Ag} / \mathrm{AgCl}$ & $\begin{array}{l}\text { Saturated Calomel } \\
\text { Electrode }\end{array}$ & $\mathrm{Ag} / \mathrm{AgCl}$ \\
\hline $\begin{array}{l}\text { Counter } \\
\text { electrode }\end{array}$ & $\mathrm{SS}$ & $\mathrm{Pt}$ & $\mathrm{Pt}$ & $\mathrm{Pt}$ & $\mathrm{Pt}$ \\
\hline WE1 & $\mathrm{Pt}$ & $\mathrm{Pt}$ & $\mathrm{Pt}$ & $\mathrm{Pt}$ & $\mathrm{Pt}$ \\
\hline WE2 & $\mathrm{Ag}$ & $\mathrm{Ir}$ & $\mathrm{Ir}$ & $\mathrm{glassy}$ Carbon & $\mathrm{glassy} \mathrm{Carbon}$ \\
\hline WE3 & $\mathrm{Au}$ & $\mathrm{Au}$ & $\mathrm{Au}$ & $\mathrm{Au}$ & $\mathrm{Au}$ \\
\hline WE4 & - & $\mathrm{Pd}$ & $\mathrm{Pd}$ & Indium Tin Oxide & - \\
\hline WE5 & - & $\mathrm{Rh}$ & $\mathrm{Rh}$ & - & - \\
\hline
\end{tabular}

The expected results are not readily available as electronics tongues output. Therefor this information from tongue has to be analyze by multi-variant statistical techniques. On the basis of given data and study being carried out statistical analysis method can be selected. The most utilized techniques to treat data from electronic tongues are different methods of patterns recognition, some of them are Cluster Analysis (CA), Discriminant Analysis (DA), Principal Component Analysis (PCA) and Artificial neural networks (ANN).

\section{EXPERIMENTATION}

\subsection{Sample Collection and Preparation}

Solapur district especially Mangalwedha tehsil is known for Jowar. M-35-1(Maldandi) Jowar is famous in all over fine milled $10 \mathrm{gm}$. jowar sample of each variety is added with $200 \mathrm{ml}$ of distilled water and kelp to dissolve for $15 \mathrm{~min}$. the sample such formed is the filtered with disposable Heat Seal Filter Paper of Size $11 \times 8 \mathrm{~cm}$ which is used for tea filtering and easily available in the market.

These three varieties have different response for moisture. Grain samples of $10 \mathrm{gm} \times 10$ of each is then continuously treated with moisture as given in the next paragraph. As the electronic tongue requires sample in liquid form, this process destroys the sample. So these 10 samples are get consumed one each day for next nine days.

$1 \mathrm{ml}$ of water is added to sample and then dried in open air for a day. Similar process is followed for next nine days. Regular measurement of moisture at the same time of the day is done and one of the sample is applied to the electronic tongue.

\subsection{Development of Sensor}

An electronic tongue setup has been developed using as array of three working electrode which are made up of different noble metals, namely gold, silver and copper; a counter electrode made-up of platinum, and an $\mathrm{Ag} / \mathrm{AgCl}$ with saturated $\mathrm{KCl}$ is used as reference electrode.

Table 2: Jowar varieties and their specification

\begin{tabular}{|l|l|l|l|}
\hline variety & M-35-1 & $\begin{array}{l}\text { Phule } \\
\text { Yashada }\end{array}$ & Mauli \\
\hline Duration & $\begin{array}{l}125-130 \\
\text { days }\end{array}$ & $\begin{array}{l}105-110 \\
\text { days }\end{array}$ & $\begin{array}{l}105-110 \\
\text { days }\end{array}$ \\
\hline Grain & $\begin{array}{l}15-18 \\
\text { Qtl./Hect. }\end{array}$ & $\begin{array}{l}60-65 \\
\text { Qtl./Hect. }\end{array}$ & $\begin{array}{l}15-20 \\
\text { Qtl./Hect. } \\
\text { (Grain) }\end{array}$ \\
\hline Fodder & $\begin{array}{l}100-105 \\
\text { Qtl./Hect. }\end{array}$ & $\begin{array}{l}160-180 \\
\text { Qtl./Hect. }\end{array}$ & $\begin{array}{l}100-140 \\
\text { Qtl./Hect. }\end{array}$ \\
\hline specialty & $\begin{array}{l}\text { Resistant to } \\
\text { water stress }\end{array}$ & $\begin{array}{l}\text { Tolerant to } \\
\text { Aphids }\end{array}$ & $\begin{array}{l}\text { Tolerant to } \\
\text { water } \\
\text { stress }\end{array}$ \\
\hline
\end{tabular}

\subsection{Cleaning and Measurement Procedure}

A measurement sequence consists of two types of waveform application and a neutralizing procedure in between and afterward to the liquefied sample. Lab-View from National Instrumentations have been employed with the help of the DAQ card USB 6009 to generate and acquire the signal. As this card is limited to generate only in the range of 0 to $5 \mathrm{v}$ of analog signal, external circuit for voltage level converter is used [6].

2.3.1 The electrochemical neutralizing or cleaning procedure of the electrode starts with a positive voltage of $2 \mathrm{~V}$ for $3 \mathrm{~s}$. Then a potential of equal but apposite sign means $-2 \mathrm{~V}$ is applied for same $3 \mathrm{~s}$.

2.3.2 Application of waveform is starts with a potential of $-0.5 \mathrm{~V}$ then it raises to $0.2 \mathrm{~V}$. Then it goes to 0.1 and so to 1 and -1 . This pattern is specially customised using LabView and a similar pattern of waveform which is used for this experimentation is shown in figure 2.

2.3.3 After application of first waveform the 2.3.1 step is repeated. 
2.3.4 The second waveform starts again with $-2 \mathrm{~V}$ and after a while a constant step size voltage of $200 \mathrm{mV}$ keeps $\mathrm{n}$ adding till it reaches +2 . This is like a staircase waveform.
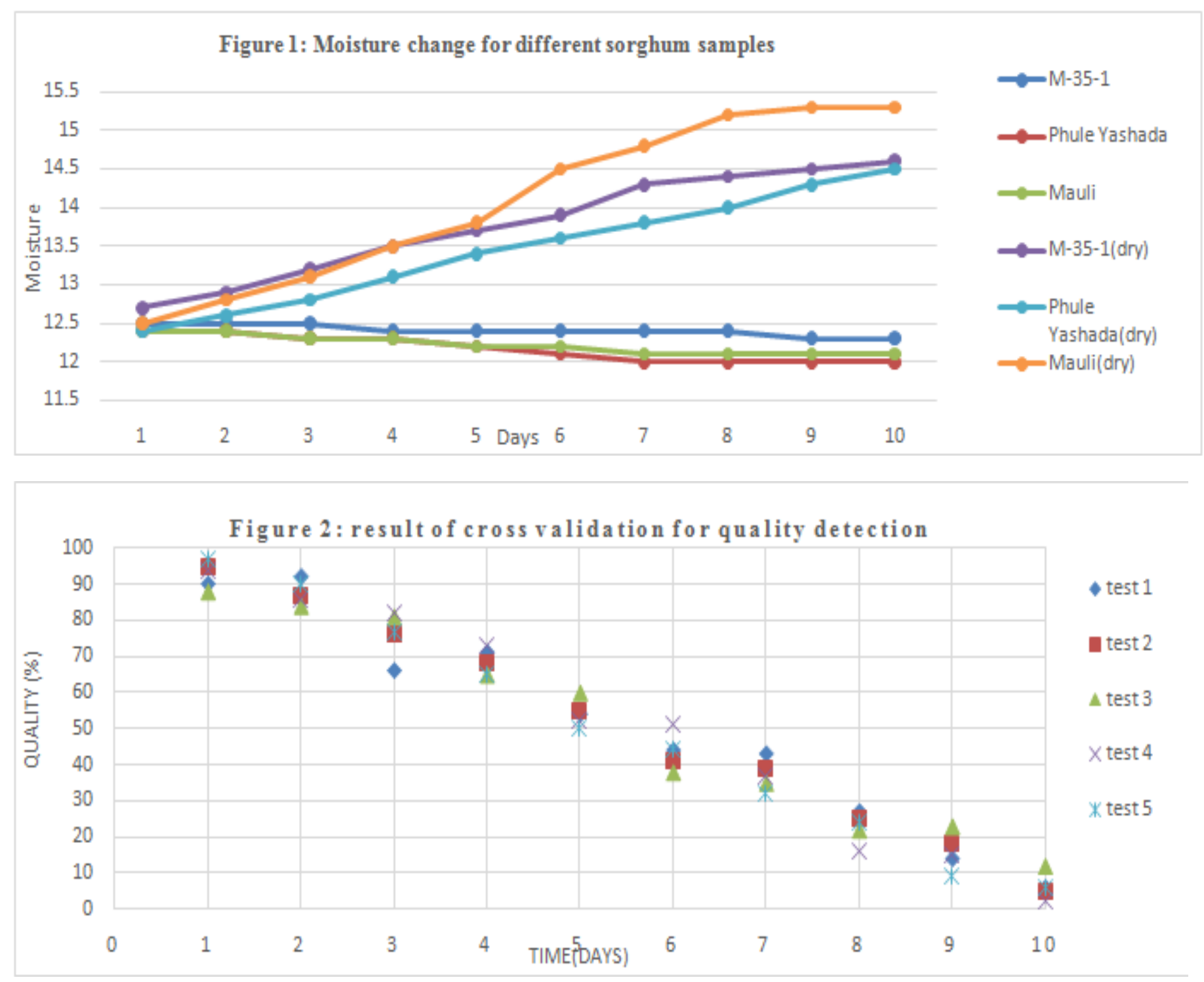

\subsection{Data Acquisition}

The electric current flowing in between each working electrode and counter electrode and voltage between reference and counter has been recorded to PC using analog inputs of DAQ card USB 6009. Such 12 repeated measurements has been recorded with time gap of $5 \mathrm{~min}$ in each measurement cycle. Each file contains 1000 readings. So such $1000 \times 12$ measurements for each WE are now available for analysis.

\section{DATA ANALYSIS}

Neural network can be used to study correlation between input and output. A commonly used topology named multilayer perceptron with different learning rule back propagation (BP-MLP), back propagation with momentum
(BPM-MLP), resilient (R-MLP) and radial basis function $(\mathrm{RBF})$ [14] is used for experimentation using electronic tongue data. As recorded data from electronic tongue is used without alteration other than normalization. So number of input neurons or nodes required was high. Here 499 input neurons are chosen with only one hidden layer which has 99 neurons.

Table 3: Results of the cross validation method for patterns

\begin{tabular}{|c|c|c|c|c|}
\hline \multirow{2}{*}{$\begin{array}{l}\text { Cross } \\
\text { validation } \\
\text { sets }\end{array}$} & \multicolumn{4}{|c|}{$\begin{array}{l}\text { Number of correctly identified data } \\
\text { patters }\end{array}$} \\
\hline & $\begin{array}{l}\text { BP- } \\
\text { MLP }\end{array}$ & $\begin{array}{l}\text { BPM- } \\
\text { MLP }\end{array}$ & $\begin{array}{l}\text { R- } \\
\text { MLP }\end{array}$ & RBF \\
\hline 1 & 8 & 9 & 8 & 10 \\
\hline 2 & 7.5 & 10 & 8 & 9 \\
\hline 3 & 8 & 9 & 9 & 9 \\
\hline
\end{tabular}




\begin{tabular}{|l|l|l|l|l|}
\hline $\mathbf{4}$ & 9 & 8 & 9 & 10 \\
\hline $\mathbf{5}$ & 8 & 8 & 8 & 9 \\
\hline $\mathbf{6}$ & 8 & 9 & 7 & 8 \\
\hline $\mathbf{7}$ & 9 & 10 & 9 & 9 \\
\hline $\mathbf{8}$ & 8 & 8 & 8.5 & 8 \\
\hline $\mathbf{9}$ & 8 & 7 & 10 & 8 \\
\hline $\mathbf{1 0}$ & 9 & 8 & 9 & 9 \\
\hline $\begin{array}{l}\text { Total } \\
\text { incorrect } \\
\text { results }\end{array}$ & 17.5 & 14 & 14.5 & 11 \\
\hline $\begin{array}{l}\text { Classificatio } \\
\text { n accuracy }\end{array}$ & $\mathbf{8 2 . 5 \%}$ & $\mathbf{8 6 \%}$ & $\mathbf{8 5 . 5 \%}$ & $\mathbf{8 9 \%}$ \\
\hline
\end{tabular}

Lowering the input neuron was able to speed up the learning and the recognition process but that again leads to false results. The learning rate is set on 0.3 for all the topologies. The output neurons will be 3 . Which will be used to discriminate the sorghum variety. In other experiment the output neuron is set to one which will give results in scale of zero to one with refers to its quality. Both of the neural networks are trained with separate samples collected and prepared in section 2.1 .

\section{RESULTS}

As sample collection of the sorghum is difficult, the size of the data set is usually small so model evaluation methods like cross-validation [15] is used to determine the efficiency of the different topologies. Here performance of the neural network is measured by classification rate. A total of 100 data patterns in the groups of $10(10 \times 10)$ is selected randomly from the total available data set.

\subsection{Classification}

In this section the three neurons chosen for three different sorghum varieties at the output layer gives one or zero for classification. When it recognizes correctly one point is awarded to that topology. Sometimes the network has given output as one for two of the output neurons in such case 0.5 points are given. The total 10 runs in a single section gives total sum of points which are recorded in to table 3 .

The results shows that even without using any type of data operation tools. The results are good. The RBF (89\%) has given the highest and BP-MLP $(82.5 \%)$ as lowest accurate result among all.

\subsection{Quality Measurement}

As given in section 2.1 samples prepared for quality analysis is given to new sets of neural network which have been trained to recognize the quality of the sample. The figure 2 shows the results of the same. Here when a constant amount of water is added to the sample its moisture content changes close to linearly (figure 1). This parameter is taken as reference for quality. And a linear scale for quality has been considered with some tolerable range of $10 \%$. Here 0 to 10 $\%$ is considered as a range and similarly other ranges are decided. When five samples tested with each range of quality, they found to be fall in the required group most of the time (figure 2).out of which maximum inaccuracy found in the range of 71 to 80 . And there was at least one inaccurate recognition found to be present. So the total accuracy found to be $68 \%$. For this, only RBF topology used to form the neural network as we found last time, it has given best result among the others.

\section{CONCLUSION}

An electronic tongue elaborated from a voltammetric sensors array was used to classifying cereals like sorghum. The electrochemical responses to the analyzed samples were collected through an electronic instrument of multi electrodes which was able to differentiate a group of substances with different taste properties. The classification of the substances was made through an ANN analysis. These results shows that the electronic tongue can also be used for quantification and quality determination of the food like cereals, further this technique should be extended to examine other cereals. Data filtering and compression may lead to more accurate results.

\section{ACKNOWLEDGMENTS}

The authors would like to thanks the farmers of the Mangalwedha, Solapur MS for helping us to collect the samples from their agricultural fields, for this study.

\section{REFERENCES}

[1]. Ivarsson, Patrik, et al. "Discrimination of tea by means of a voltammetric electronic tongue and different applied waveforms." Sensors and Actuators B: Chemical 76.1 (2001): 449-454.

[2]. Legin, Andrey, et al. "Tasting of beverages using an electronic tongue." Sensors and Actuators B: Chemical 44.1 (1997): 291-296.

[3]. Legin, Andrey, et al. "Application of electronic tongue for quantitative analysis of mineral water and wine." Electroanalysis 11.10-11 (1999): 814-820.

[4]. Kundu, Palash Kumar, Amitava Chatterjee, and P. C. Panchariya. "Electronic tongue system for water sample authentication: a slantlet-transform-based approach." Instrumentation and Measurement, IEEE Transactions on 60.6 (2011): 1959-1966.

[5]. Szollosi, D., et al. "Sweetener recognition and taste prediction of coke drinks by electronic tongue." Sensors Journal, IEEE 12.11 (2012): 3119-3123.

[6]. Palit, Mousumi, et al. "Classification of black tea taste and correlation with tea taster's mark using voltammetric electronic tongue." Instrumentation and Measurement, IEEE Transactions on 59.8 (2010): 2230-2239.

[7]. Winquist, Fredrik, et al. "Monitoring of freshness of milk by an electronic tongue on the basis of voltammetry." Measurement Science and Technology 9.12 (1998): 1937.

[8]. Cosio, Maria S., et al. "Geographical origin and authentication of extra virgin olive oils by an electronic nose in combination with artificial neural networks." Analytica Chimica Acta 567.2 (2006): 202-210. 
[9]. Deschamp, B., et al. "A voltammetric electronic tongue for detecting energetic compounds in water." Homeland Security (HST), 2012 IEEE Conference on Technologies for. IEEE, 2012.

[10]. Toko, K., et al. "Multi-channel taste sensor with lipid membranes." Technical Digest of the 9th Sensor Symposium. 1990.

[11]. Cetó, Xavier, Francisco Céspedes, and Manel del Valle. "Comparison of methods for the processing of voltammetric electronic tongues data." Microchimica Acta 180.5-6 (2013): 319-330.

[12]. Pixton, S. W. "Moisture content-its significance and measurement in stored products." Journal of Stored Products Research 3.1 (1967): 35-47.

[13]. Butt, Masood Sadiq, et al. "Effect of moisture and packaging on the shelf life of wheat flour." Internet Journal of Food Safety 4 (2004): 1-6.

[14]. Haykin, Simon, and Neural Network. "A comprehensive foundation." Neural Networks 2.2004 (2004).

[15]. Singh, Sameer, Evor L. Hines, and Julian W. Gardner. "Fuzzy neural computing of coffee and tainted-water data from an electronic nose." Sensors and Actuators B: Chemical 30.3 (1996): 185-190. 